\title{
An Investigation of the Post-laryngectomy Swallow Using Videofluoroscopy and Fiberoptic Endoscopic Evaluation of Swallowing (FEES)
}

\author{
Margaret M. Coffey ${ }^{1,6}$ (D) Neil Tolley $^{2,6} \cdot$ David Howard $^{3,6} \cdot$ Michael Drinnan $^{4}$ (D) Mary Hickson $^{5}$
}

Received: 3 May 2017 / Accepted: 7 November 2017 / Published online: 19 January 2018

(C) The Author(s) 2018. This article is an open access publication

\begin{abstract}
This study investigates the post-laryngectomy swallow. Presence and degree of residue on the post-laryngectomy swallow as observed on videofluoroscopy and FEES is described. In addition, videofluoroscopy and FEES are assessed for reliability and inter-instrument agreement. 30 laryngectomy subjects underwent dysphagia evaluation using simultaneous videofluoroscopy and FEES. These were reviewed post-examination by three expert raters using a rating scale designed for this purpose. Raters were blinded to subject details, type of laryngectomy surgery, pairing of FEES and videofluoroscopy examinations and the scores of other raters. There was a finding of residue in $78 \%$ of videofluoroscopy ratings, and $83 \%$ of FEES ratings. Comparison of the tools indicated poor inter-rater reliability and poor inter-instrument agreement. Dysphagia is an issue post laryngectomy as measured by patient self-report and by instrumental evaluation. However, alternative dysphagia rating tools and dysphagia evaluation tools are required to enable accurate identification and intervention for underlying swallow physiology post laryngectomy.
\end{abstract}

Keywords Laryngectomy · Dysphagia · FEES · Videofluoroscopy

Work performed: Imperial College London, Imperial College Healthcare NHS Trust.

Electronic supplementary material The online version of this article (https://doi.org/10.1007/s00455-017-9862-7) contains supplementary material, which is available to authorized users.

Margaret M. Coffey

margaret.coffey10@imperial.ac.uk

1 Imperial College Healthcare Trust, SLT Department, Charing Cross Hospital, Ground Floor, South Wing, Fulham Palace Road, London W6 8RF, UK

2 Imperial College Healthcare Trust, ENT Department, St Mary's Hospital, Praed Street, London W2 1NY, UK

3 Imperial College Healthcare Trust, ENT Department, Charing Cross Hospital, Fulham Palace Road, London W6 8QX, UK

4 Regional Medical Physics Dept, Freeman Hospital, Freeman Road, Newcastle upon Tyne NE7 7DN, UK

5 Institute of Health and Community, Plymouth University, Derriford Road, Plymouth, Devon PL6 8BH, UK

6 Department of Surgery and Cancer, Imperial College London, London, UK

\section{Introduction}

Laryngectomy surgery involves the anatomical separation of respiratory and swallowing systems. In contrast with other dysphagic populations, the risk of aspiration is low in this group, occurring only in the event of fistualisation or voice prosthesis leakage. Nonetheless, dysphagia is increasingly recognised [1-4] as a significant problem post laryngectomy. Some of the pathophysiological issues which may compromise swallowing ability post laryngectomy include pseudodiverticulum [4] [5, 6], fistualisation [4, 6-8], stricture [4, 9-11], fibrosis [12, 13], impaired pharyngeal propulsion [14], voice prosthesis leakage, [15-18] and reflux $[19,20]$. These difficulties may lead to impaired delayed bolus transit, bolus obstruction and sometimes bolus regurgitation. Difficulties with dysphagia post laryngectomy may result in prolonged mealtimes, compromised nutrition and weight loss [21], [3] decreased psychological wellbeing and distress [2] and diet and social interaction limitations [1]. However, in contrast to other dysphagic populations, there remains limited data on the presentation of dysphagia or the best evaluation tool to facilitate optimum management. 


\section{Instrumental Assessment of Swallowing}

\section{Videofluoroscopy (VF)}

Videofluoroscopy allows radiographic examination of the dynamic swallow process [22] and has traditionally been considered the gold standard for dysphagia evaluation [23].

A limited number of X-ray imaging studies have investigated dysphagia in the post laryngectomy patient [24-27]. Videofluoroscopy has also been combined with manometry (Videomanofluorography) to examine dysphagia post laryngectomy [5], [28] [14].

\section{Fibreoptic Endoscopic Evaluation of Swallow (FEES)}

FEES involves passing a flexible endoscope through the nose and towards the pharynx to observe swallowing in real time. FEES is a reliable and sensitive tool for assessing dysphagia [29]; given accessibility to patients and avoidance of X-ray exposure it has challenged the predominance of $\mathrm{VF}$ in the clinical setting.

FEES has been used extensively to evaluate swallowing in the head and neck cancer population, [30-36], and aspects of communication following laryngectomy [37-40]. However, the use of FEES to evaluate swallow post laryngectomy has not been reported.

\section{Simultaneous Comparison of VF and FEES}

Dysphagia can vary greatly between patients, but also from one swallow to the next in the same patient. In an instrumental comparison, the best experimental design is to evaluate the instruments on the same subject to eliminate inter-subject variability, and at the same time to eliminate intra-subject variability.

In the majority of studies [40-45] videofluoroscopy and FEES were carried out consecutively in the same patients. Performing videofluoroscopy and FEES evaluations simultaneously is technically challenging and has been described in a limited number of studies [46-49].

To date, all simultaneous and consecutive studies of videofluoroscopy and FEES have been undertaken in subjects with a larynx. This study is the first investigation of simultaneous FEES and videofluoroscopy to evaluate dysphagia in post laryngectomy patients.

\section{AIMS}

AIM 1: To describe the presence of swallow residue postlaryngectomy.
AIM 2: To describe the degree of swallow residue post laryngectomy.

AIM 3: To assess the reliability and inter instrument agreement of the two principal tools for dysphagia management; videofluoroscopy (VF) and fibre-optic endoscopic evaluation of swallowing (FEES).

\section{Methods}

Ethical approval was granted by London Riverside Research Ethics Committee (Reference number: 10/H0706/ 25).

\section{Participants}

A convenience sample of eligible patients were recruited from the outpatient surveillance caseload of a large head and neck cancer centre in the UK. We excluded participants who:

- Did not have a voice prosthesis;

- Were less than 3 months post-surgery or completion of postoperative oncological treatment;

- Had documented cognitive dysfunction;

- Were unable to tolerate placement of a flexible nasendoscope.

\section{Simultaneous Swallow Assessment}

Each subject's swallowing was examined using simultaneous videofluoroscopy and FEES.

\section{Videofluoroscopy}

The fluoroscopy unit GE Medical Systems Model UIH40CCD JK (GE, Amersham, UK) was used to capture images at a rate of 30 frames per second onto a Sony DVD recorder DVO 1000MD, (Sony, Weybridge, UK).

\section{Fibre-Optic Endoscopic Evaluation of Swallowing}

A Pentax FNL10RBS flexible nasendoscope (Pentax New Jersey, USA) was passed through right nares and advanced from the velopharyngeal port, past the base of tongue to the level of the voice prosthesis. If the subject experienced discomfort when the scope was passed through the right nares, the scope was removed and passed through the left nares. FEES exams were recorded onto the Kay Pentax Swallow Work Station Model 7127e (Pentax New Jersey, USA). 


\section{Swallow Boluses}

Each subject had 4 trial swallows in each of four consistencies. These were:

- Thin liquid (L): $10 \mathrm{ml}$ of Gastrografin radio opaque contrast (Bayer PLC, Newbury UK) with $0.5 \mathrm{ml}$ Silver Spoon green food colouring, (British Sugar PLC).

- Puree (P): $10 \mathrm{ml}$ of Ambrosia Devon custard (Premier foods, St Albans UK) with barium (made from $150 \mathrm{ml}$ of custard mixed with 3 tablespoons of E-Z-HD barium sulfate powder 98\% w/w (Bracco UK Ltd, High Wycombe, UK),

- Soft solid (S): $1 \mathrm{~cm}$ thick slice of a medium yellow banana smeared with $3 \mathrm{ml}$ of custard and barium mix, as described above.

- Hard solid $(\mathrm{H}): 1 / 4$ digestive biscuit smeared with $3 \mathrm{ml}$ barium custard mix.

\section{Swallow Bolus Imaging}

The following swallows were recorded using simultaneous VF and FEES. First, the subject was positioned in the lateral oblique plane to allow a clear view of the voice prosthesis under VF. Three trials of each consistency were given, the bolus being recorded in transit from the oral cavity to the upper esophagus. After the three trials, the subject took a water rinse swallow before moving to the next consistency.

It was considered important to observe swallows in both planes in order to screen all stages of swallowing, including the esophageal phase. Therefore, following all trials in the lateral oblique position, the subject was placed in the antero-posterior plane with the nasendoscope remaining in place. The subject then completed one further trial of each consistency, the bolus being recorded from oral cavity to esophagus. After each trial in the antero-posterior plane, the subject took a water rinse swallow.

For clarity, the order of swallows and water rinses was as follows:

Lateral-oblique: L1 L2 L3 rinse P1 P2 P3 rinse S1 S2 S3 rinse $\mathrm{H} 1 \mathrm{H} 2 \mathrm{H} 3$ rinse.

Antero-posterior: $\mathrm{L} 4$ rinse $\mathrm{P} 4$ rinse $\mathrm{S} 4$ rinse $\mathrm{H} 4$ rinse.

\section{Expert Rating of Swallows}

\section{Swallow Rating Scale}

As there was no suitable scale available for the evaluation of swallowing residue post laryngectomy, a 24-point consensus derived scale (Electronic supplementary material 1) was developed for rating of VF and FEES swallow evaluations in laryngectomy patients. Face and content validity of the scale was established through discussion and consultation with experienced members of a head and neck cancer multidisciplinary team. Additionally, laryngectomy patients provided input about the crucial aspects of their swallow difficulty and opinions on what should be included on this rating scale. The scale assessed the presence and degree of residue in the following anatomical regions of interest: neopharynx, voice prosthesis and upper esophagus. Presence of residue was indicated by answering the question "Is there residue on/in (voice prosthesis/neopharynx/esophagus) on (thin, puree, soft, solid) using a binary yes/no tick box scale. Degree of residue was measured on a visual analogue scale anchored by minimal $(00 \mathrm{~mm})$ and severe $(100 \mathrm{~mm})$.

Three expert raters were recruited, each with at least 5 years' experience in a large Head and Neck cancer centre where they manage laryngectomy patients daily. Each rater underwent 2 days of group training to maximise reliability and confirm that the rating scale was suitable for use with both videofluoroscopy and FEES.

\section{Expert Rater Evaluation}

Considering first the VF images, the recorded dynamic swallows from each patient were presented to the three raters. Participants were presented in random order, with the individual swallows segmented for each participant according to consistency described in the methods. Raters could review each swallow exam as many times as needed.

The raters scored the swallow sequence for each consistency (i.e. 3 Lateral Oblique +1 Antero-Posterior swallows) using the swallow rating scale. The entire exercise was repeated for the FEES images, with the patients in a different random order so that raters could not link examinations from the different tools. Raters evaluated videos for both videofluoroscopy and FEES examinations without audio recording to reduce recall bias.

\section{Statistical Analysis}

Data was entered and analysed in IBM SPSS version 23 (IBM Armonk, New York). Visualisation was performed in Microsoft Excel.

\section{AIM 1: Presence of Swallow Residue Post Laryngectomy}

Here we describe the overall pattern of residue, for each anatomical region of interest and bolus type, and for all anatomical regions of interest and bolus types combined, according to the expert raters. Since we used two instrumental assessments and cannot claim that either is a definitive (gold standard) measure, we report the data separately for VF and for FEES. 
As ratings related to presence of residue yielded categorical data, a consensus score for three raters was calculated from the ratings of each clinician. Consensus score was calculated when two or more raters agreed.

Agreement was then investigated between FEES and VF. A contingency table was arranged quoting the number of positive responses. Data was then analysed using McNemars to assess the differences between videofluoroscopy and FEES.

\section{AIM 2: Degree of Swallow Residue Post Laryngectomy}

As ratings related to degree of residue yielded continuous data, the difference between both FEES and Videofluoroscopy as measured in millimetres on the visual analogue scale was plotted against the mean score for each subject to produce a Bland-Altman plot, see electronic supplementary information 2 . In calculating the difference between videofluoroscopy and FEES, videofluoroscopy was subtracted from FEES, therefore a positive mean difference represents a higher score from FEES, whereas a negative mean difference represents a higher score from videofluoroscopy. A $t$ test was undertaken to assess significance.

\section{AIM 3: Reliability and Inter Instrument Agreement Using VF and FEES}

This is one of few studies to report simultaneous VF and FEES outcomes, and the only study to report these data in the post-laryngectomy swallow. If we are to use our tools reliably, then it is important to understand the agreement within and between tools.

\section{Inter-rater Reliability}

Reliability between raters was assessed by comparing the three expert assessments of each swallow sequence, for each anatomical region of interest. Reliability for Videofluoroscopy and FEES was investigated using free marginal kappa for categorical data. Free marginal Kappa was chosen because raters were not forced to assign a certain number of cases to each category and therefore had free rather than fixed marginals. In addition, as this study involved more than two raters, the multirater free marginal Kappa was used to examine both intra and inter rater reliability for categorical data. Intraclass Correlation Coefficient (ICC). was used to examine intra and inter rater reliability for continuous data.

Inter instrument agreement was analysed using Fleiss kappa.
Table 1 Demographic characteristics

\begin{tabular}{|c|c|}
\hline Age & 66.3 (SD 8.6) years range $43-81$ years \\
\hline Time since surgery & $\begin{array}{l}89.9 \text { (SD 63.3) months range } \\
4-225 \text { months }\end{array}$ \\
\hline \multicolumn{2}{|l|}{ Gender } \\
\hline Female & $6(20 \%)$ \\
\hline Male & $24(80 \%)$ \\
\hline \multicolumn{2}{|l|}{ Ethnicity } \\
\hline Black/black british & $1(3 \%)$ \\
\hline White & $26(87 \%)$ \\
\hline Asian/asian british & $3(10) \%$ \\
\hline \multicolumn{2}{|l|}{ Tumour type } \\
\hline $\mathrm{T} 1$ & $1(3 \%)$ \\
\hline $\mathrm{T} 2$ & $4(13 \%)$ \\
\hline T3 & $7(23 \%)$ \\
\hline $\mathrm{T} 4$ & $11(37 \%)$ \\
\hline Unknown & $7(23 \%)$ \\
\hline \multicolumn{2}{|l|}{ Surgery } \\
\hline Total laryngectomy & $22(73 \%)$ \\
\hline Pectoralis major flap & $3(10 \%)$ \\
\hline Radial forearm flap & $1(3 \%)$ \\
\hline Jejunum flap & $3(10 \%)$ \\
\hline $\begin{array}{l}\text { Jejunum and pectoralis } \\
\text { major flap }\end{array}$ & $1(3 \%)$ \\
\hline \multicolumn{2}{|l|}{ Myotomy } \\
\hline Yes & $24(80 \%)$ \\
\hline Not applicable & $3(10 \%)$ \\
\hline Unknown & $3(10 \%)$ \\
\hline \multicolumn{2}{|l|}{ Radiotherapy Hx } \\
\hline None & $3(10 \%)$ \\
\hline Pre-operative XRT & $13(43 \%)$ \\
\hline Postoperative XRT & $12(40 \%)$ \\
\hline Pre \& postoperative XRT & $2(7 \%)$ \\
\hline \multicolumn{2}{|l|}{ Chemotherapy Hx } \\
\hline Pre op chemo & $5(17 \%)$ \\
\hline No chemo & $25(83 \%)$ \\
\hline \multicolumn{2}{|l|}{ Salvage surgery } \\
\hline Yes & $17(57 \%)$ \\
\hline No & $13(43 \%)$ \\
\hline
\end{tabular}

\section{Results}

A complete set of images was obtained for 30 subjects; two subjects were excluded due to failure of endoscopy recording equipment. Demographic characteristics are outlined in Table 1. 
Table 2 Differences between tools-presence of residue

\begin{tabular}{|c|c|c|c|c|c|}
\hline \multirow[t]{2}{*}{ Parameter } & \multicolumn{2}{|c|}{ Videofluoroscopy } & \multicolumn{2}{|l|}{ FEES } & \multirow{2}{*}{$\begin{array}{l}P<0.001 \\
P\end{array}$} \\
\hline & Consistency & $\%$ & Consistency & $\%$ & \\
\hline \multirow{8}{*}{$\begin{array}{l}\text { Percentage of positive } \\
\text { responses for presence of } \\
\text { neopharynx residue }\end{array}$} & \multirow[t]{2}{*}{ Thin liquids } & $100 \%$ & \multirow[t]{2}{*}{ Thin liquids } & $23.3 \%$ & $0.001 *$ \\
\hline & & $24 / 30$ & & $0 / 0$ & N/A \\
\hline & \multirow[t]{2}{*}{ Puree } & $83.3 \%$ & \multirow[t]{2}{*}{ Puree } & $6.6 \%$ & $0.001 *$ \\
\hline & & $25 / 29$ & & $0 / 0$ & N/A \\
\hline & \multirow[t]{2}{*}{ Soft } & $86.6 \%$ & \multirow[t]{2}{*}{ Soft } & $13.3 \%$ & $0.001 *$ \\
\hline & & $20 / 28$ & & $2 / 2$ & 1.0 \\
\hline & \multirow[t]{2}{*}{ Solid } & $80 \%$ & \multirow[t]{2}{*}{ Solid } & $6.6 \%$ & $0.001 *$ \\
\hline & & $24 / 30$ & & $0 / 0$ & N/A \\
\hline \multirow{8}{*}{$\begin{array}{l}\text { Percentage of positive } \\
\text { responses for presence of } \\
\text { voice prosthesis residue }\end{array}$} & \multirow[t]{2}{*}{ Thin liquids } & $73.3 \%$ & \multirow[t]{2}{*}{ Thin liquids } & $80 \%$ & 0.18 \\
\hline & & $22 / 30$ & & $25 / 28$ & 0.5 \\
\hline & \multirow[t]{2}{*}{ Puree } & $90 \%$ & \multirow[t]{2}{*}{ Puree } & $0 \%$ & $0.001 *$ \\
\hline & & $27 / 30$ & & $27 / 27$ & 0.3 \\
\hline & \multirow[t]{2}{*}{ Soft } & $80 \%$ & \multirow[t]{2}{*}{ Soft } & $93 \%$ & 0.22 \\
\hline & & $24 / 30$ & & $25 / 26$ & 0.4 \\
\hline & \multirow[t]{2}{*}{ Solid } & $66.6 \%$ & \multirow[t]{2}{*}{ Solid } & $93.3 \%$ & 0.39 \\
\hline & & $21 / 30$ & & $27 / 27$ & 0.008 \\
\hline \multirow{8}{*}{$\begin{array}{l}\text { Percentage of positive } \\
\text { responses for presence of } \\
\text { upper esophageal residue }\end{array}$} & \multirow[t]{2}{*}{ Thin liquids } & $90 \%$ & \multirow[t]{2}{*}{ Thin liquids } & $93.3 \%$ & 1.0 \\
\hline & & $27 / 30$ & & $26 / 28$ & 1.0 \\
\hline & \multirow[t]{2}{*}{ Puree } & $96.6 \%$ & \multirow[t]{2}{*}{ Puree } & $93.3 \%$ & 1.0 \\
\hline & & $29 / 30$ & & $27 / 27$ & 1.0 \\
\hline & \multirow[t]{2}{*}{ Soft } & $80 \%$ & \multirow[t]{2}{*}{ Soft } & $93.3 \%$ & 0.75 \\
\hline & & $24 / 30$ & & $24 / 26$ & 0.3 \\
\hline & \multirow[t]{2}{*}{ Solid } & $66.6 \%$ & \multirow[t]{2}{*}{ Solid } & $96.6 \%$ & $0.001 *$ \\
\hline & & $20 / 30$ & & $29 / 29$ & 0.002 \\
\hline
\end{tabular}

Missing values removed. Proportions are expressed as number positive/number rated

\section{AIM 1: Presence of Residue in the Post- laryngectomy Swallow}

Table 2 shows the results relating to presence of residue in anatomical regions of interest with different consistencies. This data came from rating scale categorical questions "Is there residue on/in the (voice prosthesis/neopharynx/ esophagus) on (thin liquids/puree/soft/solid) and represents the percentage of positive responses for each tool. The raters systematically found it much easier to identify residue in the neopharynx using videofluoroscopy compared to FEES whatever the consistency. For residue on the voice prosthesis there was little difference between the tools, except for puree. For esophageal residue FEES was different to videofluoroscopy on solid consistency only.

\section{AIM 2: Degree of Residue}

Videofluoroscopy scored a greater degree of neopharyngeal residue on all consistencies, see Table 3. The degree of voice prosthesis residue was similar for both tools on all consistencies except for thin liquids when FEES scored a greater degree of residue. Both tools showed a similar degree of esophageal residue for puree and soft consistencies. However FEES scored a greater degree of esophageal residue on thin liquids and solids. While each of these differences were statistically significant it is noted that limits of agreement between tools are wide.

\section{AIM 3: Comparison of Features Using VF and FEES}

\section{Intra- and Inter-rater Reliability}

Detailed results are contained in electronic supplementary material 3 and show the following:

Intra-rater reliability of free marginal kappa $>0.6$ was achieved on $100 \%$ of categorical questions, (odd numbered questions on the rating scale-see electronic supplementary material 1). Inter-rater reliability for categorical data 
Table 3 Differences between tools—degree of residue

\begin{tabular}{|c|c|c|c|c|}
\hline \multirow{3}{*}{$\begin{array}{l}\text { Parameter } \\
\begin{array}{l}\text { Degree of neopharynx } \\
\text { residue }\end{array}\end{array}$} & \multicolumn{2}{|c|}{$\begin{array}{l}\text { Mean difference* } \\
(95 \mathrm{CI})\end{array}$} & \multirow{2}{*}{$\begin{array}{l}t \text {-test } P \\
\text { value }<0.05 \\
0.001\end{array}$} & \multirow{2}{*}{$\begin{array}{l}\text { Limits of agreement (mm) } \\
-42.09 \text { LL to } 20.12 \mathrm{UL}\end{array}$} \\
\hline & Thin liquids & $-10.98(-16.90,-5.05)$ & & \\
\hline & $N=1$ & N/A & N/A & N/A \\
\hline & Puree & $-20.11(-28.67,-11.55)$ & 0.001 & $-65.03 \mathrm{LL}$ to $24.81 \mathrm{UL}$ \\
\hline & $N=1$ & N/A & N/A & N/A \\
\hline & Soft & $-14.55(-23.74,-5.36)$ & 0.003 & - $62.79 \mathrm{LL}$ to $33.69 \mathrm{UL}$ \\
\hline & $N=2$ & $\begin{array}{l}+20.5(60.34) \\
-521.5 \text { to }+562.6\end{array}$ & 0.7 & -97.8 to +138.8 \\
\hline & Solid & $-19.44(-29.72,-9.17)$ & 0.001 & 34.48 LL to $73.36 \mathrm{UL}$ \\
\hline & $N=2$ & $\begin{array}{l}+35.1(42.78) \\
-349.3 \text { to }+419.4\end{array}$ & 0.5 & -48.7 to +118.9 \\
\hline \multirow{8}{*}{$\begin{array}{l}\text { Degree of voice } \\
\text { prosthesis residue }\end{array}$} & Thin liquids & $22.03(13.93,30.12)$ & 0.001 & $-20.26 \mathrm{LL}$ to $64.42 \mathrm{UL}$ \\
\hline & $N=28$ & $\begin{array}{l}+27.0(24.48) \\
+17.5 \text { to }+36.5\end{array}$ & $<0.001$ & -21.0 to +75.0 \\
\hline & Puree & $0.72(-7.51,-8.95)$ & 0.859 & $42.48 \mathrm{LL}$ to $43.93 \mathrm{UL}$ \\
\hline & $N=29$ & $\begin{array}{l}+3.8(25.12) \\
-5.80 \text { to }+13.31\end{array}$ & 0.4 & -45.4 to +53.0 \\
\hline & Soft & $9.11(-0.87,19.1)$ & 0.72 & $-43.3 \mathrm{LL}$ to $61.52 \mathrm{UL}$ \\
\hline & $N=28$ & $\begin{array}{l}+16.5(28.78) \\
+5.3 \text { to }+27.6\end{array}$ & 0.005 & -39.9 to +72.9 \\
\hline & Solid & $5.88(-3.46,15.22)$ & 0.21 & $-43.16 \mathrm{LL}$ to $54.92 \mathrm{UL}$ \\
\hline & $N=28$ & $\begin{array}{l}+8.6(26.90) \\
-1.9 \text { to }+19.0\end{array}$ & 0.1 & -44.1 to +61.3 \\
\hline \multirow[t]{7}{*}{$\begin{array}{l}\text { Degree of esophageal } \\
\text { residue }\end{array}$} & $\begin{array}{l}\text { Thin liquids } \\
N=28\end{array}$ & $\begin{array}{l}18.58(11.76,25.39) \\
+28.6(22.97) \\
+19.7 \text { to }+37.5\end{array}$ & $\begin{array}{l}0.00 \\
<0.001\end{array}$ & $\begin{array}{l}-17.19 \mathrm{LL} \text { to } 54.36 \mathrm{UL} \\
-16.4 \text { to }+73.6\end{array}$ \\
\hline & Puree & $5.57(-72,11.85)$ & 0.81 & $-27.05 \mathrm{LL}$ to $38.19 \mathrm{UL}$ \\
\hline & $N=29$ & $\begin{array}{l}+10.8(3.73) \\
+3.2 \text { to }+18.4\end{array}$ & 0.007 & +3.5 to +18.1 \\
\hline & Soft & $10.3(2.32,18.28)$ & 0.13 & -31.6 to $52.2 \mathrm{UL}$ \\
\hline & $N=27$ & $\begin{array}{l}+18.0(21.96) \\
+9.3 \text { to }+26.7\end{array}$ & $<0.001$ & -25 to +61.0 \\
\hline & Solid & $7.93(0.14,15.72)$ & 0.046 & 32.95 (LL) to $48.81 \mathrm{UL}$ \\
\hline & $N=29$ & $\begin{array}{l}+10.0(21.09) \\
+2.0 \text { to }+18.0\end{array}$ & 0.02 & -31.3 to +51.3 \\
\hline
\end{tabular}

*Mean difference $=$ mean visual analogue scale measurement for FEES - mean visual analogue scale measurement for VF. Min-Max $=0-100$ with a higher score meaning more residue. A positive difference = a higher score from FEES; a negative difference $=$ a higher score from $\mathrm{VF}$ $L L$ lower limit, $U L$ upper limit, VF videofluoroscopy, FEES Fibreoptic Endoscopic Evaluation of Swallow

was less robust with free marginal kappa of $>0.6$ achieved on $33 \%(4 / 12)$ of questions for videofluoroscopy and $42 \%$ $(5 / 12)$ for FEES. Intra-rater reliability of ICC $>0.6$ was achieved on $58 \%(7 / 12)$ of continuous questions (even numbered questions on the rating scale- see electronic supplementary material 3). Inter-rater reliability of ICC $>0.6$ for continuous data was achieved on $25 \%(3 / 12)$ questions for videofluoroscopy and 33\% (4/12) questions for FEES.
Given the majority of missing data under FEES, we excluded the neopharynx from the analysis in both instruments to give a direct comparison. Overall agreement is summarised in Table 4, using Fleiss kappa.

Observed pairwise agreement was reasonably good, but there was heavy bias with about $80 \%$ of all ratings being positive (see Fig. 1). Consequently, the probability of agreement by chance is almost $70 \%$; this maps to kappa $=0$. We present the kappa statistic with some 
Table 4 Summary of agreement between 3 raters on 240 swallow sequences. For FEES, exclusions were recorded when one or more raters were unable to rate a sequence. (All swallows are tabulated)

\begin{tabular}{|c|c|c|c|c|c|c|}
\hline & All - ( $\square \square \square)$ & One + ( $\square \square \square)$ & Two + ( $\square \square \square)$ & Three + ( $\square \square \square)$ & Excluded & Agreement \\
\hline FEES & 0 & 8 & 66 & 144 & 22 & $\begin{array}{l}77 \% \text { observed } \\
\text { Kappa }=0.18\end{array}$ \\
\hline VF & 3 & 43 & 67 & 127 & 0 & $\begin{array}{l}69 \% \text { observed } \\
\text { Карра }=0.10\end{array}$ \\
\hline
\end{tabular}

Green indicates no residue, red indicates presence of residue

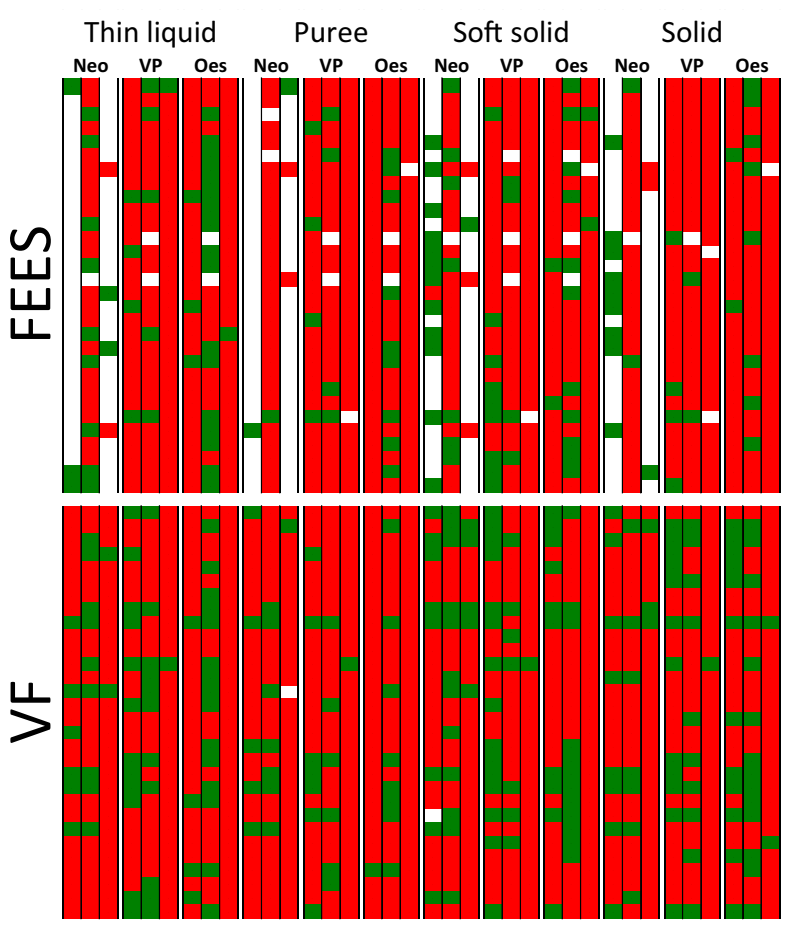

Fig. 1 The results of simultaneous swallow assessments on 30 patients by two instruments (FEES and VF) and 3 expert raters. Residue was assessed for 4 food consistencies (thin liquid, puree, soft solid, solid) and on 3 anatomical structures (neopharynx, voice prosthesis, upper esophagus), by 3 raters. The columns represent these ratings. Each row represents one patient. A red square indicates 'residue present', and green indicates 'no residue'. If the rater could not make a judgment, then the square is white. In total, there are 30 patients $\times 3$ raters $\times 4$ consistencies $\times 3$ features $=1080$ ratings for VF, and ratings of the same 1080 swallow sequences for FEES. The order of patients is the same for VF and for FEES. Therefore (for example), the top left square in the top and bottom panel relates to the same swallow sequence

reservations, because it is considered to give a pessimistic view of reliability under these circumstances.

Primarily, the better agreement for FEES came from the 180 cases with full consensus that the sequence was abnormal. Raters scored more 'normal' sequences on VF and consensus on these was poor, albeit better for VF. This can be seen in Fig. 1 where agreement about the green
Table 5 Summary of agreement between VF and FEES on 218 swallow sequences where the three raters reached consensus on the outcome for both instruments

\begin{tabular}{lccr}
\hline & VF $-(\square \square)$ & VF $+(\square \square)$ & Total \\
\hline FEES $+(\square)$ & 39 & 171 & 210 \\
FEES $-(\square)$ & 2 & 6 & 8 \\
Total & 41 & 177 & 218 \\
\hline
\end{tabular}

The 22 excluded swallow sequences are the same as those recorded in Table 4. (Non excluded swallows tabulated only)

Green indicates no residue, red indicates presence of residue

boxes is clearly better for $\mathrm{VF}$, though still poor. We also note that 22 sequences could not be rated on FEES.

\section{Inter-instrument Agreement}

As earlier, we excluded the neopharynx from this assessment given that most of these swallow sequences were unrateable on FEES. The results are shown in Table 5.

Overall pairwise agreement was 173/218 swallow sequences, or $79 \%$ (kappa $=-0.03$ ). The agreement between FEES and VF is exactly what one would expect by chance alone. This is evident from Fig. 1, where there is poor correspondence in green areas between the top and bottom panels.

Considering now the overall bias, there was a significant bias towards FEES scoring more positive findings (McNemar's test, $P<0.001$ ). This is indicated by the discordant pairs in Table 2, top-left and bottom-right. In 39/45 cases, the FEES scored the positive and the VF was negative (odds ratio $=6.5,95 \%$ CI 2.7-18.8).

\section{Discussion}

This study provides preliminary evidence for the presentation of dysphagia following laryngectomy. We assessed the patients using the same tools, methods and expert 
reviewers that manage dysphagia in the non-laryngectomy population.

\section{AIM 1: Presence of Residue in the Post Laryngectomy Swallow}

The first objective of this study was to ascertain which dysphagia evaluation tool more accurately identified presence of residue in the neopharynx, on the voice prosthesis and in the upper esophagus. Presence of residue is important for laryngectomy patients because it may delay the swallow, may necessitate the need to alternate food with swallow to clear residue and causes patients to swallow more than once. Poor pharyngeal clearance post laryngectomy resulting in residue has previously been described [28, 14]. Videofluoroscopy provided greater identification than FEES on all consistencies in the neopharynx. It is possible that raters may have found it easier to identify this area on the broader field of view provided by videofluoroscopy X-ray image than on the surface anatomy view provided by FEES. Videofluoroscopy also scored more highly than FEES for the identification of puree residue on the voice prosthesis. This could be due to the propensity of the puree material (custard) to collect on the tip of the endoscope thereby obscuring the view on FEES but not on videofluoroscopy. The raters were therefore unable to rate puree on FEES because they were unable to see anything. The use of a less glutinous puree consistency may have reduced adhesion of puree to the tip of the endoscope. A significant limitation of this study is the presence of missing values as a result of the inability of raters to view residue particularly in the neopharyx. Identification of residue in the upper esophagus was similar on both tools except for solid for which FEES appeared to offer an advantage. Further research would be beneficial to ascertain whether this is an incidental finding or indicative of the difficulty inherent in coating a solid bolus with sufficient barium to ensure comprehensive identification of residue on videofluoroscopy. This study involved coating the solid biscuit bolus with a barium preparation. Utilising a biscuit baked with barium may have yielded a different result.

\section{AIM 2: Degree of Residue}

The next objective of this study was to investigate degree of residue. Poor mucosal clearance resulting in residue has previously been described as a feature of post laryngectomy swallowing $[14,28]$. The greater the degree of residue, the longer and more laborious mealtimes may become for patients. Videofluoroscopy scored higher for identifying degree of residue in the neopharynx. However, for the upper esophagus and on the voice prosthesis, videofluoroscopy and FEES scored similarly, with the exception of thin liquids on the voice prosthesis and thin liquids and solids in the esophagus. Thus, it would appear that for examining the degree of residue in the neopharynx VF is better, whilst for the voice prosthesis and upper esophagus both FEES and VF may be used.

Interestingly, a previous study [14] indicated that dysphagia was not self reported by some patients despite evidence of significant residue. It may be worth considering whether some degree of residue should be regarded as 'normal' post laryngectomy. If some residue is judged as normal in the post-laryngectomy swallow, then we must define 'abnormality' to identify how much residue constitutes normality.

If we consider residue of any amount to be abnormal, then on the evidence of this study we may need to offer every laryngectomy patient the opportunity of some intervention, such as strengthening tongue base retraction to promote bolus clearance through the reconstructed pharynx. However, we need tools with the specificity to more clearly delineate the nature of the underlying swallowing physiology causing dysphagia post laryngectomy.

\section{AIM 3: Comparison of Features Using VF and FEES}

In order to explore which tool (VF or FEES) may be better for assessing laryngectomy swallow we had to rate the findings from these assessments. Interpretation of a swallowing image, whether elicited from videofluoroscopy or from FEES, is largely based on visual judgment and is inherently subjective in nature. The rating scale used in this study to measure expert raters judgment showed poor intrarater reliability for FEES images, and the poor inter-rater reliability for both videofluoroscopy and FEES. Previous studies [50-52] have also identified poor inter-rater reliability on various parameters of videofluoroscopy swallow evaluation highlighting the subjective nature of these assessments. Free marginal kappa was used to evaluate reliability for categorical data. Free marginal kappa is approximately equivalent to Fleiss/Cohen kappa under best possible conditions where there are equal numbers of each category to be assigned. In the absence of best possible conditions, free marginal kappa is likely to be higher than Fleiss/Cohen kappa. In our study inter-rater reliability was worse for continuous data than for categorical data, where continuous data was derived from visual analogue scales (VAS) to indicate degree of residue. Previously VAS have been proposed as a more precise method of measuring residue compared to categorical scales [53, 54], but our data suggest that reliability is poor and so further research is required to find the best way to evaluate degree of residue. Bolus consistency has been identified as a factor affecting rater agreement levels on FEES [55] with lower 
agreement for thin liquid than for thick liquid. The impact of consistency on observer agreement remains underexplored and may require further investigation in relation to this study which utilised multiple consistencies. Part of the training for the expert raters in this study included group discussion and comparison of rated images and this may have improved inter-rater reliability because others [56] have indicated that levels of agreement are lowest when raters worked alone in judging videofluoroscopy.

In our group of patients, the summary reliability of the data as measured by the kappa statistic is poor. There are two likely explanations: first, we suspect this task has particular challenges for clinicians who may re-calibrate their internal reference to this group of patients to varying degrees. For example, consider FEES, thin liquid, esophagus in Fig. 1. One of the three raters scored 17 normal swallows whereas the other two scored three and one respectively. This suggests that one rater has a completely different internal reference as to what is 'normal' compared to the other two. One would expect that experts would have far better agreement. Secondly, the kappa statistic has known idiosyncrasies. We reported an observed agreement (i.e. the number of times when a pair of raters agreed) of around $80 \%$. In a balanced task with equal numbers of positive and negative cases this would correspond to kappa $=0.6$, considered subjectively 'good' agreement [57]. In our sample kappa is around 0.1. The proponents of kappa would point out that the context of the rating task is important. Here we are measuring a group of patients at one extreme (i.e. without a larynx). In this specific situation where there is relatively little variability between patients, the rating scale must have better resolution and accuracy. There is a direct analogy with other measuring instruments. A weighing scale that is designed for adult patients up to $150 \mathrm{~kg}$ would not be the right tool to measure neonates who are all in the range of $2-10 \mathrm{~kg}$. We need a more specific tool in this patient group.

The agreement between VF and FEES was even worse, and indeed was no better than chance (kappa $=-0.03$ ). The statistical interpretation of this finding is worth exploring. If one picked any two swallow ratings completely at random, you would expect those ratings to agree about $80 \%$ of the time, purely by chance. We observed 79\% agreement between VF and FEES. This is slightly worse even than chance would predict, so kappa was slightly negative. Since we do not have a gold standard in this study, and since neither instrument showed a relationship with self-reported swallow problems, we cannot say which, if any, instrument has clinical value. Nevertheless, we report significantly more positive findings on FEES. This is in keeping with a previous study, [47] where using a 4-point residue scale there was a consistent difference of about 1 point between FEES (higher) and VF (lower) using simultaneous measurement. As with Kelly's work, without a gold standard it is not possible to say which is correct. FEES is the more sensitive tool, but may in some circumstances be detecting a thin coating of residue that is clinically unimportant i.e. a false positive.

\section{Conclusion}

This study has demonstrated that dysphagia is an issue post laryngectomy with residue a significant symptom as measured by instrumental evaluation. However, this study has also highlighted the issues with rater reliability in both identifying presence and degree of residue. As a consequence of the low aspiration risk presented post laryngectomy, the areas of both dysphagia evaluation and intervention have remained largely under explored in this population. While both videofluoroscopy and FEES may be beneficial for evaluating aspects of post laryngectomy swallowing, further research is required to optimize the use of these and alternative tools in this patient cohort. The ability to identify symptoms of dysphagia using evaluation tools with established reliability is likely to become increasing important to enable appropriate interventions to be developed for this sub group of head and neck cancer patients.

Acknowledgements Sarah Adams, Yvonne Edels and Sarah Pilsworth kindly provided expert rating of videofluoroscopy and FEES swallows.

Disclaimer The views expressed are those of the authors and not necessarily those of the NHS, the NIHR or the Department of Health.

Open Access This article is distributed under the terms of the Creative Commons Attribution 4.0 International License (http://crea tivecommons.org/licenses/by/4.0/), which permits unrestricted use, distribution, and reproduction in any medium, provided you give appropriate credit to the original author(s) and the source, provide a link to the Creative Commons license, and indicate if changes were made.

Funding This research was funded by a NIHR Clinical Doctoral Fellowship (Project number CDRF-09-14).

\section{References}

1. Ward E, Frisby J, Stephens M. Swallowing outcomes following Laryngectomy and Pharyngolaryngectomy. Arch Otolaryngol Head Neck Surg. 2002;128(2):181-6.

2. Maclean J, Cotton S, Perry A. Post Laryngectomy: it's hard to swallow. An Australian study of prevalence and self reports of swallow function after total laryngectomy. Dysphagia. 2009;24(2):172.

3. Maclean J, Cotton S, Perry A. Dysphagia following a total laryngectomy? The effect on quality of life, functioning and psychological well being. Dysphagia. 2009;24(3):314. 
4. Landera M, Lundy D, Sullivan P. Dysphagia after total laryngectomy. Perspectives on Swallowing and Swallowing Disorders. J asha. 2010;19(2):39-44.

5. Kirchner J, Scatliff J, Dey F, Shedd D. The pharynx after laryngectomy. Changes in it's structure and function. Laryngoscope. 1963;73(1):18-33.

6. Sullivan PA, Hartig GK. Dysphagia after total laryngectomy. Curr Opin Otolaryngol Head Neck Surg. 2001;9(3):139-46.

7. Hanasano M, Lin D, Wax M, Rosenthal E. Closure of laryngeal defects in the age of chemoradiation therapy. Head Neck. 2012;34(4):580-8.

8. McLean JN, Nicholas C, Duggal P, Chen A, Grist WG, Losken A, Carlson GW. Surgical management of pharyngocutaneous fistula after total laryngectomy. Ann Plast Surg. 2012;68(5):442-5. https://doi.org/10.1097/SAP.0b013e318225832a.

9. Silverman J, Deschler D. A novel approach for dilation of neopharyngeal stricture following total laryngectomy using the tracheosophageal puncture site. Laryngoscope. 2008;118:2011-3.

10. Sweeny L, BlakeGolden J, White H, ScottMagnusson J, Carroll W, Rosenthal E. Incidence and outcomes of stricture formation post laryngectomy. Otolaryngol Head Neck Surg. 2012;146(3): 395-402.

11. Harris R, Grundy A, Odutoye T. Radiologically guided balloon dilatation of neopharyngeal strictures following total laryngectomy and pharyngolaryngectomy: 21 years experience. J Laryngol Otol. 2010;124:175-9.

12. King SN, Dunlap NE, Tennant PA, Pitts T. Pathophysiology of radiation-induced dysphagia in head and neck cancer. Dysphagia. 2016;31(3):339-51. https://doi.org/10.1007/s00455-016-9710-1.

13. Langmore S, Krisciunas G. Dysphagia after radiotherapy for head and neck cancer: etiology, clinical presentation, and efficacy of current treatments. Perspect Swallowing Swallowing Disord. 2010;19(2):32-8.

14. Maclean J, Szczesniak M, Cotton S, Perry A. Impact of a laryngectomy and surgical closure technique on swallow biomechanics and dysphagia severity. Otolaryngol Head Neck Surg. 2011;144(1):21-8.

15. Choussy O, Hibon R, Bon Mardion N, Dehesdin D. Management of voice prosthesis leakage with Blom-Singer large esophage and tracheal flange voice prostheses. Eur ann otorhinolaryngol, head and neck dis. 2013;130(2):49-53. https://doi.org/10.1016/j.anorl. 2012.03.008.

16. Lorenz KJ. The development and treatment of periprosthetic leakage after prosthetic voice restoration. A literature review and personal experience part I: the development of periprosthetic leakage. European archives of oto-rhino-laryngology: official journal of the European Federation of Oto-Rhino-Laryngological Societies (EUFOS): affiliated with the German Society for OtoRhino-Laryngology. Head Neck Surg. 2015;272(3):641-59. https://doi.org/10.1007/s00405-014-3394-7.

17. Lorenz KJ. The development and treatment of periprosthetic leakage after prosthetic voice restoration: a literature review and personal experience. Part II: conservative and surgical management. European archives of oto-rhino-laryngology: official journal of the European Federation of Oto-Rhino-Laryngological Societies (EUFOS): affiliated with the German Society for OtoRhino-Laryngology. Head Neck Surg. 2015;272(3):661-72. https://doi.org/10.1007/s00405-014-3393-8.

18. Lewin JS, Hutcheson KA, Barringer DA, Croegaert LE, Lisec A, Chambers MS. Customization of the voice prosthesis to prevent leakage from the enlarged tracheoesophageal puncture: results of a prospective trial. Laryngoscope. 2012;122(8):1767-72.

19. Garrido CM, Fernández L, Varela HV, Gálvez MN. Study of laryngopharyngeal reflux using $\mathrm{pH}$-metering in immediate postop of laryngectomized patients. Acta Otorrinolaringol Esp. 2007;58(7):284-9.
20. Bock JM, Brawley MK, Johnston N, Samuels T, Massey BL, Campbell BH, Toohill RJ, Blumin JH. Analysis of pepsin in tracheoesophageal puncture sites. Ann Otol Rhinol Laryngol. 2010; 119(12):799-805. https://doi.org/10.1177/000348941011901203.

21. Ackerstaff AH, Hilgers FJM, Aaronson NK, Balm AJM. Communication, functional disorders and lifestyle changes after total laryngectomy. Clin otolaryngol allied sci. 1994;19(4):295-300.

22. Martin-Harris B, Logemann JA, McMahon S, Schleicher M, Sandidge J. Clinical utility of the modified barium swallow. Dysphagia. 2000;15(3):136-41.

23. Logemann J. Instrumental techniques for the study of swallowing. In: Logeman J, editor. Evaluation and treatment of swallowing disorders. 2nd ed. Texas: Pro Ed; 1998. p. 53-70.

24. Schobinger R. Spasm of the cricopharyngeal muscle as cause of dysphagia after total laryngectomy. AMA Arch Otolaryngol. 1958;67(3):271-5.

25. Vrticka K, Svoboda M. A clinical and x-ray study of 100 laryngectomized speakers. Folia phoniatrica. 1961;13:174-86.

26. Jung TT, Adams GL. Dysphagia in laryngectomized patients. Otolaryngol Head Neck Surg. 1980;88(1):25-33.

27. Balfe DM, Koehler RE, Setzen M, Weyman PJ, Baron RL, Ogura $\mathrm{JH}$. Barium examination of the esophagus after total laryngectomy. Radiology. 1982;143(2):501-8.

28. McConnel FM, Mendelsohn MS, Logemann JA. Examination of swallowing after total laryngectomy using manofluorography. Head Neck Surg. 1986;9(1):3-12.

29. Kamarunas EE, McCullough GH, Guidry TJ, Mennemeier M, Schluterman K. Effects of topical nasal anesthetic on fiberoptic endoscopic examination of swallowing with sensory testing (FEESST). Dysphagia. 2014;29(1):33-43. https://doi.org/10. 1007/s00455-013-9473-x.

30. Langmore S, Schatz K, Olsen N. Fiberoptic endoscopic examination of swallow safety: a new procedure. Dysphagia. 1988;2:216-9.

31. Leder S, Sasaki C. Use of FEES to assess and manage patients with head and neck cancer. In: Langmore S, editor. Endoscopic Evaluation and Treatment of Swallowing Disorders. New York: Thieme; 2001. p. 178-87.

32. Hiss S, Postma G. Fiberoptic evaluation of swallowing. Laryngoscope. 2003;113(8):1386-93.

33. Rosenthal DI, Lewin JS, Eisbruch A. Prevention and treatment of dysphagia and aspiration after chemoradiation for head and neck cancer. J Clin Oncol. 2006;24(17):2636-43. https://doi.org/10. 1200/jco.2006.06.0079.

34. Teguh D, Levendag P, Sewnaik A, Hakkesteegt M, Noever I, Voet P, van der Est H, Sipkema D, van Rooij P, Baatenburg de Jong RJ, Schmitz PIM. Results of fiberoptic endoscopic evaluation of swallowing vs. radiation dose in the swallowing muscles after radiotherapy of cancer in the oropharynx. Radiother Oncol. 2008;89(1):57.

35. Deutschmann MW, McDonough A, Dort JC, Dort E, Nakoneshny S, Matthews TW. Fiber-optic endoscopic evaluation of swallowing (FEES): predictor of swallowing-related complications in the head and neck cancer population. Head Neck. 2013;35(7): 974-9. https://doi.org/10.1002/hed.23066.

36. VanAs C, OpDeCoul B, Eysholdt U, Hilgers F. Value of digital high-speed endoscopy in addition to videofluoroscopic imaging of the neoglottis in tracheoesophageal speech. Acta Otolaryngol. 2004;124(1):82-9.

37. Mohri M, Yoshifuji M, Kinishi M, Amatsu M. Neoglottic activity in tracheoesophageal phonation. Auris Nasus Larynx. 1994;21(1):53.

38. Oh CK, Meleca RJ, Simpson ML, Dworkin JP. Fiberoptic examination of the pharyngoesophageal segment in tracheoesophageal speakers. Arch otolaryngol head neck surg. 2002; 128(6):692-7. 
39. Pilsworth S. Routine use of nasendoscopy to enhance the speech and language therapist's decision- making process in surgical voice restoration. Otolaryngol Head Neck Surg. 2011;145(1): 86-90. https://doi.org/10.1177/0194599811401312.

40. Nayar RC, Sharma VP, Arora MM. A study of the pharynx after laryngectomy. J laryngol otol. 1984;98(8):807-10.

41. Langmore S, Schatz K, Olson N. Endoscopic and videofluroscopic evaluations of swallowing and aspiration. Ann Otol Rhinol Laryngol. 1991;100:396-401.

42. Bastian R. The videoendoscopic swallowing study: an alternative and partner to the videofluroscopic swallowing study. Dysphagia. 1993;8:359-67.

43. Wu CH, Hsiao TY, Chen JC, Chang YC, Lee SY. Evaluation of swallowing safety with fiberoptic endoscope: comparison with videofluoroscopic technique. Laryngoscope. 1997;107(3): 396-401.

44. Perie S, Laccourreye L, Flahault A, Hazebroucq V, Chaussade S, St Guily JL. Role of videoendoscopy in assessment of pharyngeal function in oropharyngeal dysphagia: comparison with videofluoroscopy and manometry. Laryngoscope. 1998;108(11 Pt 1): $1712-6$.

45. Madden C, Fenton J, Hughes J, Timon C. Comparison between videofluoroscopy and milk-swallow endoscopy in the assessment of swallowing function. Clin Otolaryngol Allied Sci. 2000; 25(6):504-6.

46. Rao N, Brady S, Chaudhuri G, Donzelli J, Wesling M. GoldStandard? analysis of the videofluoroscopic and fiberoptic endoscopic swallow examinations. JApplied Res. 2003;3:1-8.

47. Kelly AM, Leslie P, Beale T, Payten C, Drinnan MJ. Fibreoptic endoscopic evaluation of swallowing and videofluoroscopy: does examination type influence perception of pharyngeal residue severity? Clin otolaryngol. 2006;31(5):425-32. https://doi.org/10. 1111/j.1749-4486.2006.01292.x.

48. Kelly AM, Drinnan MJ, Leslie P. Assessing penetration and aspiration: how do videofluoroscopy and fiberoptic endoscopic evaluation of swallowing compare? Laryngoscope. 2007;117(10): 1723-7. https://doi.org/10.1097/MLG.0b013e318123ee6a.

49. Pisegna JM, Langmore SE. Parameters of Instrumental Swallowing Evaluations: describing a diagnostic dilemma. Dysphagia. 2016;31(3):462-72. https://doi.org/10.1007/s00455-016-9700-3.
50. Stoeckli SJ, Huisman TA, Seifert B, Martin-Harris BJ. Interrater reliability of videofluoroscopic swallow evaluation. Dysphagia. 2003;18(1):53-7. https://doi.org/10.1007/s00455-002-0085-0.

51. McCullough GH, Wertz RT, Rosenbek JC, Mills RH, Webb WG, Ross KB. Inter- and intrajudge reliability for videofluoroscopic swallowing evaluation measures. Dysphagia. 2001;16(2):110-8. https://doi.org/10.1007/PL00021291.

52. Kuhlemeier KV, Yates P, Palmer JB. Intra- and interrater variation in the evaluation of videofluorographic swallowing studies. Dysphagia. 1998;13(3):142-7.

53. Pisegna JM, Langmore SE Rating residue: categorical ratings versus a visual analog scale. In: Dysphagia Research Society Annual Meeting, Chicago, IL,2017. https://doi.org/10.13140/RG. 2.2.23934.38725.

54. Pisegna JM, Kaneoka A, Leonard R, Langmore SE. Rethinking residue: determining the perceptual continuum of residue on FEES to enable better measurement. Dysphagia. 2017;. https:// doi.org/10.1007/s00455-017-9838-7.

55. Pilz W, Vanbelle S, Kremer B, van Hooren MR, van Becelaere T, Roodenburg N, Baijens LW. Observers' agreement on measurements in fiberoptic endoscopic evaluation of swallowing. Dysphagia. 2016;31(2):180-7. https://doi.org/10.1007/s00455015-9673-7.

56. Scott A, Perry A, Bench J. A study of inter rater reliability when using videofluroscopy as an assessment of swallowing. Dysphagia. 1998;13(4):223-7.

57. Landis JR, Koch GG. The measurement of observer agreement for categorical data. Biometrics. 1977;33(1):159-74.

Margaret M. Coffey Cert MRCSLT, PhD

Neil Tolley MD, FRCS, DLO

David Howard MB

Michael Drinnan $\mathrm{PhD}$

Mary Hickson RD, PhD 